\title{
EL DEBATE POSCOLONIAL LATINOAMERICANO Y SUS EXTENSIONES PRÁCTICAS HACIA LA DESCOLONIZACIÓN DEL SABER EN EL PRÓLOGO DEL SIGLO XXI.
}

\author{
Edorta Camino-Esturo ${ }^{1}$
}

Resumen: En este trabajo, se reflejan algunas aportaciones al debate poscolonial de diversos intelectuales latinoamericanos con el fin de contravenir el saber hegemónico occidental o, al menos, conseguir un reconocimiento de los saberes indígenas y subalternos en igualdad de oportunidades. La identidad de las culturas latinoamericanas está condicionada por siglos de colonización occidental que ha impulsado unas culturas híbridas (Bhabha, 2002), no exentas de conflicto social y político. Es necesaria la superación de la hegemonía occidental dominante hacia un diálogo de saberes que revalorice el papel poscolonial de las epistemologías del sur con el objetivo de lograr unas identidades emancipadas y no coloniales. A través de la construcción de este discurso crítico, surgen unos nuevos contextos donde aplicar la teoría poscolonial y poder iniciar un proceso de descolonización de las mentes latinoamericanas durante el siglo XXI.

Palabras clave: Poscolonialismo. Descolonización del Saber. Saber Hegemónico. Hibridez.

Abstract: This paper aims to reflect on the postcolonial debate of various Latin American intellectuals who struggle against Western hegemonic knowledge or, at least, for the recognition of indigenous and subaltern knowledge in equal opportunities. The identity of Latin American cultures is conditioned by centuries of Western colonization that has produced hybrid cultures (Bhabha, 2002), with social and political conflict too. It is necessary to overcome the dominant Western hegemony towards a dialogue of knowledge that revalues the postcolonial role of the epistemologies of the south with the aim of achieving emancipated and non-colonial identities. Through the construction of this critical discourse, new contexts arise to apply the postcolonial theory and to initiate a process of decolonization of the Latin American minds during the 21 st century.

Keywords: Postcolonialim. Decolonizing Knowledge. Hegemonic Knowledge. Hibridity.

\footnotetext{
${ }^{1}$ Universidad del País Vasco | Euskal Herriko Unibertsitatea. Doctor en Ciencias Sociales, Universidad Pública de Navarra (UPNA). E-mail: edortagune@ hotmail.com.
}

REALIS, v.7, n. 01, Jan-Jun. 2017 - ISSN 2179-7501 


\section{Introducción.}

La teoría poscolonial y los estudios críticos subalternos son una aportación fundamental en la elaboración de un discurso alternativo frente al discurso occidental dominante. Los procesos de globalización impulsados por la economía neoliberal generan una uniformización de las culturas en base a valores y estéticas occidentales. En América Latina, existen muchas voces competentes que disienten y postulan por otras formas de comprender el mundo, por desarrollar otras actitudes que ayuden a reconstruir las identidades y las cosmovisiones latinoamericanas $\mathrm{y}$, así mismo, las de cualquier otra cultura que haya sido discriminada o perseguida por los procesos colonizadores y neocolonizadores que se dan a lo largo de la historia mundial.

El objetivo de este trabajo es comparar las aportaciones teóricas de algunos de estos intelectuales latinoamericanos que, junto con otros autores internacionales (Edward Said, Homi Bhabha, Boaventura de Sousa Santos, Catherine Walsh, etc.), tratan de descolonizar las mentes de América Latina y señalar cuáles son los caminos que se han de seguir para encontrar una práctica poscolonizadora que enseñe también los conocimientos y saberes de las culturas subalternas, nativas, ancestrales, originarias y no hegemónicas.

La metodología del estudio se basa en una revisión bibliográfica de los textos de diferentes referentes de la literatura poscolonial y subalterna latinoamericana (Castro-Gómez, 1998 y 2005; Dussel, 2000; Lander, 2000; Mignolo, 1995; Quijano, 2000; entre otros) que, en diálogo con esos autores internacionales mencionados anteriormente, conforman una red intelectual crítica que posibilita, en consecuencia, la construcción de una masa social contrahegemónica y poscolonial a nivel global.

En este sentido, el artículo construye un enfoque particular sobre el concepto de poscolonialismo interrelacionado con la descolonización del saber o la superación de la modernidad, en palabras de Enrique Dussel (2000). El poscolonialismo se presenta como un concepto ambiguo y peligroso (Mignolo, 1995; Santos, 2002), atado al bagaje colonial y eurocéntrico que domina y condiciona la descolonización de las mentes latinoamericanas. La hibridez (Bhabha, 2002) es una variable dependiente de la cultura y los saberes latinoamericanos que multiplica las identidades para poder renunciar a la "escalera" de la 
modernidad, a unas nuevas formas de conocimiento y emancipación que no sigan el camino marcado por los saberes hegemónicos y coloniales.

\section{Un enfoque sobre la teoría poscolonial en América Latina.}

El argentino Walter Mignolo (1995) constata que lo poscolonial o la poscolonialidad es "una expresión ambigua, algunas veces peligrosa, otras veces confusa y generalmente limitada e inconscientemente empleada". Esta ambigüedad viene dada por la acepción sociohistórica relacionada con la "expansión colonial y la descolonización” que, en algunos países se dieron en lugares y momentos históricos diferentes, algunos en el siglo XIX. Por lo tanto, es posible hablar en esas situaciones de poscolonialismo con un significado enlazado con el periodo posterior a la colonización. Según Mignolo, al igual que Robotham (1996), es peligrosa en el momento en que el término se convierte, a nivel académico, en una "fuente principal en contra de las prácticas de oposición para la gente de color, intelectuales del tercer mundo o grupos étnicos en la academia”. La confusión aparece cuando

expresiones como hibridización, mestizaje, espacio entre medio y otras expresiones equivalentes se convierten en el objeto de reflexión y crítica de las teorías postcoloniales porque ellas sugieren una discontinuidad entre la configuración colonial del objeto o tema de estudio y la posición postcolonial del lugar de la teoría (Mignolo, 1995, p. 91).

Partiendo de esta base, un compatriota de Mignolo, Miguel Mellino (2008), comparte la ambigüedad del término "poscolonial" dentro del conflicto entre una acepción literal o metafórica. Mellino sugiere que "el surgimiento de conflictos típicos del mundo colonial dentro de la sociedad descolonizada representa uno de los rasgos fundamentales del mundo poscolonial" (Mellino, 2008, p. 30). Mellino acude a las explicaciones de Stwart Hall (1996):

El término "poscolonial" ciertamente no designa a una de esas periodizaciones basadas en "estadios" epocales donde de pronto todo cambia contemporáneamente, todas las viejas relaciones desaparecen para siempre y otras enteramente nuevas vienen a sustituirlas. Claramente, desengancharse del proceso colonizante ha sido una tarea larga, extendida y diferenciada, en la que los más recientes movimientos posbélicos de descolonización figuran como sólo uno de los momentos "distintivos". Aquí, "colonización" está para indicar ocupación y gobierno colonial directo, y la transición al "poscolonial" está caracterizada por la independencia del gobierno colonial directo, la formación de nuevos estados nacionales, el crecimiento económico, el incremento del capital local y de las relaciones de dependencia neocoloniales del mundo capitalista desarrollado, así como 
también por las políticas que surgen con la emergencia de poderosas élites locales que controlan los efectos contradictorios del subdesarrollo. Es igualmente significativo que tal transición esté caracterizada por la persistencia de muchos de los efectos de la colonización, sólo que ahora éstos han sufrido una dislocación: se han corrido del eje colonizador/colonizado y se han interiorizado en la misma sociedad descolonizada. [...] En este escenario, lo "colonial" no ha muerto, desde el momento en que continúa viviendo en sus secuelas (Mellino, 2008, p. 30$31)$.

También en los años 90, Don Robotham escribía que el término poscolonial "ha sido objeto de numerosos comentarios y críticas en los últimos años". Robotham expone que abarca "el periodo que siguió a la independencia política en el antiguo mundo colonial", además de "la fase más reciente de dicho periodo", en la cual surgieron "los escritos de los intelectuales sobre los nuevos y espinosos temas surgidos de este periodo de desencanto del anticolonialismo" relacionados con los "dilemas agónicos" y sus "amargas decepciones" que, según Robotham, constituyen "el punto central del proyecto poscolonial” (Robotham, 1996, p. 1).

Para Santos (2002), el poscolonialismo es un producto del "cambio cultural" de las ciencias sociales en la década de los 80, teniendo como principales precursores a Frantz Fanon (1999) y a Albert Memrni (1974). Los cuales fueron la antesala de los pioneros trabajos de Edward Said en Orientalismo (1990) y de Stuart Hall (1996), y de otros autores, sobre todo del ámbito hindú, como Homi Bhabha (2002) o Gayatri Spivak (1990). Especialmente, son autores que han nacido en los países colonizados por la órbita del Imperio Británico, pero que su vida laboral académica ha transcurrido en Occidente (Santos, 2002, p. 13).

Según Santos, el poscolonialismo debe ser entendido en sus dos acepciones principales. La primera sería el periodo histórico que sucede a las independencias de las colonias, es decir, lo que ocurre después-del-colonialismo, aunque hayan surgido otras relaciones económicas, políticas o sociales a partir de esos procesos dentro de su inserción en el sistema mundial. Y la segunda acepción se refiere al conjunto de prácticas y discursos que deconstruyen la narrativa colonial escrita por el colonizador y procuran sustituirla por narrativas escritas desde el punto de vista del colonizado. Dentro de este concepto se encontrarían los estudios culturales, lingüísticos y literarios que usan principalmente la exégesis textual y las prácticas performativas para analizar los sistemas de representación y 
los procesos identitarios, que llevan implícita o explícitamente, los silencios del análisis poscolonial de la primera acepción (Santos, 2002, p. 26).

El término poscolonial implica la enfatización de la presencia europea sobre las sociedades o individuos que han sido colonizados. Estos están identificados con esa “experiencia colonial y se omite toda consideración de su historia anterior (esto es, de otras formas de dominación, de otras intervenciones sanguinarias, de otras imposiciones culturales)" (Vega, 2003, p. 24), reduciendo la poscolonialidad a una "centralidad abusiva al hecho de la colonización europea". De esta manera, cuando

la crítica metropolitana habla de postcolonialidad convierte la dominación europea en la experiencia fundante de la historia de los territorios colonizados, respecto de la cual esa misma historia se periodiza y se nombra. Todas las culturas sometidas por una potencia occidental quedarían así acomunadas por su distancia respecto de esa dominación colonial y compartirían una relación, por así decir, preposicional, con Europa, ya que su historia estaría marcada por -y subordinada a- el inicio y la conclusión de la presencia europea, por un pre- y por un post-. Otros términos, en cambio, como colonialismo o colonial, aluden a la experiencia innegable del imperio desde un punto de vista político, pero no le conceden un valor fundacional (Vega, 2003, p. 24).

El debate en torno a lo poscolonial trata sobre el "imperativo de revisitar y reescribir la modernidad occidental para obligarla a confesar algo que no necesariamente quiere ni desea“, donde el "choque de mundos y culturas diversas que entran en Occidente" ceda el paso a un reto mucho más "radical" de establecer "otro Occidente". Partiendo de esta situación multicutlural, de diversidad cultural, se encuentre un "punto heterogéneno" donde se pueda vivir siendo distinto "en una época planetaria en la que Occidente, a pesar de su continuado poder económico, político y cultural, no sea siempre el amo" (Chambers, 2006, p. 215).

Esta "hibridización creativa" del discurso poscolonial puede ser considerada como resultado de una crítica de dos "metanarrativas opuestas" que han fomentado la interpretación histórica y geográfica del desarrollo desigual: la metanarrativa del capitalismo y la metanarrativa del socialismo. Para Soja (2008), existe una "escisión metanarrativa" en los estudios realizados sobre la globalización, dividiendo entre "aquellos que consideran la globalización de una forma optimista, en tanto portadora de nuevas oportunidades para el desarrollo, la modernización y la democracia", y aquellos que opinan que "con el surgimiento del capitalismo global se están intensificando las injusticias y las divisiones socio-espaciales". Algunas de las críticas poscoloniales se mueven entre perspectivas, orientándolas en “direcciones nuevas e innovadoras, especialmente en relación con las oportunidades de 
progreso asociadas a la reafirmación de lo local, del poder de las identidades basadas en el lugar, del desarrollo de contranarrativas de la nación" (Soja, 2008, p. 292).

En el momento en que desaparece definitivamente el antiguo régimen colonial y tambalea "el equilibrio del orden mundial establecido durante la guerra fría" (Castro-Gómez, 1998, p. 169), surgen las teorías posmodernas y poscoloniales: "aquellos discursos contramodernos", provenientes de diferentes lugares de enunciación, que "procuran dar cuenta de las herencias coloniales de la modernidad”. Para Castro-Gómez, las teorías posmodernas encuentran su "locus de enunciación en sujetos del «Primer Mundo» marginalizados por la dinámica capitalista de la modernidad", mientras que las teorías poscoloniales se "vinculan a sujetos del «Tercer Mundo» que viven o provienen de sociedades con fuertes herencias coloniales".

En muchos casos, los sujetos de la teorización poscolonial son intelectuales nacidos en regiones subalternizadas por la modernidad europea que trabajan ahora en academias o universidades de países ex o neocolonialistas. Su actitud crítica frente a la modernidad es, en este sentido, diferente a la de los intelectuales posmodernos del «centro», pues se funda en una determinada «sensibilidad geocultural», en los vínculos afectivos que mantienen con su región de origen, en un sentido de territorialidad ligado, sobre todo, a la práctica del idioma materno (Castro-Gómez, 1998, p. 169).

Aún así, el texto poscolonial suele estar escrito en "la lengua de los colonizadores, como única vía de comunicación y propagación", aunque sea un texto "altamente híbrido que persigue afianzar la identidad cultural" (Messeguer, 2006, p. 2). El caso concreto de la literatura poscolonial africana se identifica por un "sustrato común", formado por "factores culturales, ideológicos y estéticos que son el resultado de la experiencia colonial en el continente africano". La característica poscolonial del texto africano es que se trata de un texto "híbrido" en el cual se dan una confluencia de distintas tradiciones orales y escritas. Messeguer, sin embargo, niega la realidad única del texto africano porque la herencia colonial observada en el mapa de África con sus fronteras "trazadas con un cuchillo, como una gran tarta cuyos pedazos se repartieron los colonizadores", ha producido una gran variedad de textos diferentes en un mismo pueblo, cuya realidad se encuentra dividida por esas fronteras impositivamente heredadas. Para Messeguer, el discurso poscolonial nace como "un discurso de oposición con la única idea de buscar un espacio de afirmación donde afianzar la identidad propia" (Messeguer, 2006, p. 3).

Estos intelectuales han visualizado que "la razón moderna no echa su fundamento en el desarrollo intrínseco de las humanidades y la filosofía en Europa, es decir en las herencias 
espirituales del Renacimiento y la Ilustración, sino en las prácticas coloniales establecidas por Europa en ultramar". De esta forma, los intelectuales poscoloniales logran alterar "los cánones académicos que reservan al «Primer Mundo» la confección de saberes teóricamente relevantes" (Castro-Gómez, 1998, p. 169).

Los estudios poscoloniales fueron introducidos en la academia por Edward Said, a partir de la publicación de Orientalismo en 1978. El objetivo era demostrar las consecuencias del colonialismo y del imperialismo, en una discusión binaria entre el colonizador y el colonizado,

El nexo entre conocimiento y poder que crea "al oriental" y que en cierto sentido lo elimina como ser humano para mí no es una cuestión exclusivamente académica, es una cuestión intelectual de una importancia evidente. He podido valerme de mis preocupaciones humanísticas y políticas para analizar y describir una materia muy concreta, el nacimiento, desarrollo y consolidación del orientalismo. Con demasiada frecuencia, se presupone que la literatura y la cultura son inocentes política e históricamente. Yo siempre he creído lo contrario, y este estudio de orientalismo me ha convencido (y espero que les suceda lo mismo a mis colegas literarios) de que la sociedad y la cultura literaria sólo se pueden comprender y estudiar juntas. [...] Pero también me gustaría haber contribuido a mejorar el conocimiento del modo en que la dominación cultural ha actuado. Si esto fomenta un nuevo tipo de relación con Oriente, -de hecho, si elimina "Oriente" y "Occidente" totalmente-, habremos avanzado algo en el proceso de lo que Raymond Williams ha llamado el "desaprehendimiento del espíritu inherente de dominación" (Said, 1990, p. 49).

Siguiendo la explicación de Castro-Gómez, la idea central de Orientalismo es que "la dominación imperial de Europa sobre sus colonias de Asia y el Medio Oriente durante los siglos XIX y XX condujo, necesariamente, a la institucionalización de una cierta imagen o representación sobre «el oriente»y «lo oriental»”.Una de las características del poder imperial es que "el dominio no se consigue tan solo matando y sometiendo al otro por la fuerza sino que requiere de un elemento ideológico o «representacional»", es decir, requiere de "un discurso sobre el «otro»" y la afiliación de ese discurso en el "habitus de dominadores y dominados" de Europa sobre sus colonias hubiera resultado "imposible". Para esta misión, el dominador europeo inventó al "«otro» como objeto de conocimiento (oriente)" y construyó también una "imagen autocentrada" de su propio lugar de enunciación (occidente) en el proceso de establecer el dominio (Castro-Gómez, 2005, p. 21), porque las representaciones fueron "elementos fundamentales para el establecimiento del dominio colonial de occidente", para la construcción de unos imaginarios capaces de generar "formas de vida y pensamiento" que se encuentran, no sólo en los actores, sino también en "estructuras concretas, como son: 
"leyes de Estado, códigos comerciales, planes de estudio en las escuelas, proyectos de investigación científica, reglamentos burocráticos, formas institucionalizadas de consumo cultural", es decir, va más alla de la conciencia del colonizado sino que le sirve de "vivencia de una materialidad objetiva (Castro-Gómez, 2005, p. 22). Para Castro-Gómez, es particularmente interesante

el papel que Said otorgó a las ciencias humanas en la construcción de este imaginario colonial. El orientalismo encontró su lugar en la academia metropolitana desde el siglo XIX con la creación de cátedras sobre «civilizaciones antiguas» en el marco del gran entusiasmo generado por el estudio de las lenguas orientales. Said afirmó que el dominio imperial de Gran Bretaña sobre la India permitió el acceso irrestricto de los eruditos a los textos, los lenguajes y las religiones del mundo asiático, hasta ese momento desconocidas para Europa (Castro-Gómez, 2005, p. 23).

Said examina el orientalismo como un discurso, a través del cual "la cultura europea ha sido capaz de manipular - e incluso dirigir- Oriente desde un punto de vista político, sociológico, militar, ideológico, científico e imaginario a partir del periodo posterior a la Ilustración" (Said, 1996, p. 11).

La cultura puede ser un auténtico campo de batalla en el que las causas se expongan a la luz del día y entren en liza unas con otras, mostrando que, por ejemplo, los estudiantes norteamericanos, franceses o indios, a quienes se ha enseñado a leer a sus clásicos nacionales por encima de otros, están obligados a apreciarlos y a pertenecer lealmente, muchas veces de manera acrítica, a sus naciones y tradiciones al mismo tiempo que denigran o luchan unas contra otras. El problema de esta idea de cultura es que supone no sólo la veneración de lo propio sino también que eso propio se vea, en su cualidad trascendente, como separado de lo cotidiano. Así, muchos de los humanistas profesionales se ven incapaces de establecer conexiones entre la crueldad prolongada y sórdida de prácticas como la esclavitud, o la opresión racial y colonialista, o la sujeción imperial en el seno de una sociedad, por un lado, y, por otro, la poesía, la ficción y la filosofía de esa misma sociedad (Said, 1996, p. 14).

Para Said, la cultura puede "predisponer a una sociedad a prepararse para la dominación ultramarina de otra, e incluso ser parte activa de tal dominación”, pero también puede, de manera contraria, contribuir a modificar esta situación mediante la voluntad de los y las colonizadas de provocar un cambio en esa situación, "de desplegar ideas de liberación y de imaginar una nueva comunidad nacional capaz del salto final". Un cambio que también es fundamentado en el agotamiento de las relaciones económicas y políticas con el imperio que pueda originar un coste del régimen colonial, creando una pérdida de imagen del imperialismo y, por ende, una ruptura de su "justificación” y su "legitimidad" (Said, 1996, p. 312). Said expone que 
de la misma exacta manera en que durante el período de auge imperialista se tendía a permitir únicamente un discurso cultural que surgiese del interior metropolitano, hoy el posimperialismo deja que emerja el discurso de la cultura de la sospecha por parte de los pueblos antes colonizados, mientras que los intelectuales metropolitanos practican un teoricismo que evita los puntos conflictivos (Said, 1996, p. 303).

En una conferencia impartida en 1999, veinte años después de Orientalismo, en la Universidad Americana de El Cairo, Edward Said defiende, en palabras del sociólogo brasileño Emir Sader (Said, 2009, p. 82), la autonomía del espacio académico como fuente de conocimiento crítico, emancipación y justicia, confesando que:

Tengo muy poca paciencia con el tipo de etnocentrismo pregonado por Samuel Huntington y otros como él que afirman que la totalidad de las ideas de democracia, libertad e ilustración son ideas occidentales, cuando los hechos históricos son, como ahora sabemos en referencia a la educación, muy heterogéneos, muy variados, mucho más una cuestión de contribución hecha por toda la humanidad, todos los pueblos, todas las culturas. No hay una fuente única para nada: todos los pueblos comparten la construcción de la historia, todos los pueblos hacen la historia (Said, 2009, p. 85).

Para Said, la libertad académica debería ser como la del emigrante o el viajero, ya que "si en el mundo real fuera de la academia podemos necesitar ser nosotros mismos y sólo nosotros mismos, dentro de la academia, [...] deberíamos ser capaces de descubrir y viajar a través de otros sí mismos, otras identidades, otras variedades de la aventura humana". En la unión de este "sí mismo" y el "otro", el papel de la academia es "transformar lo que podría ser conflicto, o combate, o afirmación, en reconciliación, reciprocidad, reconocimiento, interacción creativa". Sin embargo, Said opina que, desde la academia, habría que asumir riesgos a la hora de afrontar el conocimiento, porque éste no debe ser una forma de coerción ni control, la exploración del conocimiento sirve para comprender e, incluso, asumir más de una manera de ser. La academia es "un lugar en el que viajar, sin apropiarnos de nada de ella, pero sintiéndonos en casa en cualquier lugar en ella. No puede haber un saber prohibido si la universidad moderna mantiene su lugar, su misión, su poder para educar” (Said, 2009, p. 90).

La independencia nacional significó que "la juventud finalmente pudiera ser enteramente educada en las tradiciones, historias, idiomas y culturas de sus propios países". Said fue educado en las esculeas coloniales británicas donde "todo estaba enfocado en la historia de la sociedad británica, su literatura y valores". En estas colonias se daba por sentado que las elites nativas serían aleccionadas sobre la cultura intelectual, a través de "los lenguajes y métodos concebidos, de hecho, para mantener a aquellas elites nativas básicamente serviles al gobierno colonial, a la superioridad del saber europeo" (Said, 2009, p. 91). Es por ello la 
importancia que tiene la reclamación de un "territorio" educativo propio, poscolonial, que fue "tanto tiempo dominado por gobernantes extranjeros" que les enseñaban "normas y valores distantes más que a los nuestros", de los cuales "había que avergonzarse" por ser tenida como de "menor categoría", lo cual dejó una "terrible herida espiritual”" (Said, 2009, p. 91).

Finalmente, Homi Bhabha, en el libro El lugar de la cultura (2002), expone unas diferencias con las teorías poscoloniales basadas en las estructuras binarias, que argumenta Said y otros teóricos, para explicar la visión de Occidente sobre Oriente. La perspectiva dual del blanco/negro, Yo/Otro, Occidente/Oriente, etc, Bhabha lo trastoca con la idea de hibridez o hibridación (hibridity), como un tercer espacio que se encuentra en las múltiples fronteras culturales (Sharp, 2009, p. 121). Bhabha utiliza la metáfora de la escalera, basada en la artista afroamericana Renée Green, según la cual la diferencia cultural y la multiculturalidad es representada como "una escalera liminar, una senda entre áreas más altas y más bajas, cada una de las cuales estaba inscripta con placas que se referían a la negritud y la blancura" (Bhabha, 2002, p. 20). Bhabha interpreta la escalera como un

espacio liminal, entre-medio de las designaciones de identidad, se torna el proceso de la interacción simbólica, el tejido conectivo que construye la diferencia entre lo alto y lo bajo, entre negro y blanco. El movimiento de la escalera, el movimiento temporal y el desplazamiento que permite, impide que las identidades en los extremos se fijen en polaridades primordiales. Este pasaje intersticial entre identificaciones fijas abre la posibilidad de una hibridez cultural que mantiene la diferencia sin una jerarquía supuesta o impuesta (Bhabha, 2002, p. 20).

Bhabha alude al "imaginario de la distancia espacial”, es decir, a "vivir más allá de la frontera de nuestros tiempos", para elaborar un presente que no sea entendido de manera causal como "un puente con el pasado y el futuro", sino como un lugar en el cual los límites epistemológicos de las ideas etnocéntricas sean también

los límites enunciativos de un espectro de otras historias y otras voces disonantes, incluso disidentes: mujeres, colonizados, minorías, portadores de sexualidades vigiladas. Pues la demografía del nuevo internacionalismo es la historia de la migración poscolonial, las narrativas de la diáspora cultural y política, los grandes desplazamientos sociales de campesinos y aborígenes, las poéticas del exilio, la sombría prosa de los refugiados políticos y económicos (Bhabha, 2002, p. 21).

Para Bhabha, la metrópoli occidental debe "enfrentar su historia poscolonial, contada por su ingreso de migrantes y refugiados en la posguerra, como una narrativa indígena o nativa interna o inherente a su identidad nacional", y el motivo para esto "queda claro en el tartamudeante discurso ebrio del señor 'Whisky' Sisodia en Los versos satánicos: El 
problema con el in-inglés es que su his-his-historia sucedió al otro lado de los mares, por eso no-no-no saben qué significa" (Bhabha, 2002, p. 23).

La poscolonialidad, por su parte, es un saludable recordatorio de las persistentes relaciones "neocoloniales" dentro del "nuevo" orden mundial y la división multinacional del trabajo. Tal perspectiva hace posible la autentificación de historias de explotación y la evolución de estrategias de resistencia. Más allá de esto, empero, la crítica poscolonial da testimonio de los países y las comunidades (del norte y del sur, urbanas y rurales) constituidas, si se me permite la frase, "de otro modo que con la modernidad". Esas culturas de una contramodernidad poscolonial pueden ser contingentes a la modernidad, discontinuas o enfrentadas a ella, resistentes a sus tecnologías opresivas y asimilacionistas; pero también despliegan la hibridez cultural de sus condiciones fronterizas para "traducir", y en consecuencia reinscribir, el imaginario social de la metrópoli y la modernidad (Bhabha, 2002, p. 23).

\section{La praxis de un proceso hacia la descolonialidad del saber.}

El proceso colonizador originó, así mismo, una colonización de los saberes nativos, los cuales estaban considerados salvajes y protocientíficos. La ciencia se convirtió en un saber hegemónico y explicativo de cualquier fenómeno natural o social, excluyendo cualquier episteme que estuviera fuera de la ciencia moderna. Actualmente, uno de los objetivos de los intelectuales poscoloniales trata sobre cómo llevar a la práctica una descolonización del saber hegemónico, en beneficio de los saberes ancestrales o, al menos, en condiciones equitativas con la ciencia moderna. En palabras de Dávalos,

Existe una sospecha con respecto a la ciencia moderna, una especie de "mancha de nacimiento", por decirlo de alguna manera, que provoca suspicacias con respecto al orden del saber que ella estructura, consolida y reproduce. Esa sospecha radica en la simbiosis, muchas veces explícita y connivente, del saber con el poder. De acuerdo a esta suspicacia con el saber moderno, no se conoce para cambiar ni transformar al mundo, menos aún para descubrir qué es la realidad ni porqué está conformada tal como es; se conoce para dominar, para someter, para subordinar, para controlar (Dávalos, 2013, p. 1).

En el caso de América Latina existe un "malestar con el conocimiento moderno como mera estrategia del poder", reflejada en los escritos de Ernesto Sábato, y en la propuesta de la colonialidad y decolonialidad del saber/poder, que tiene en los nombres de Aníbal Quijano, Enrique Dussel, Arturo Escobar, Walter Mignolo, Edgardo Lander, Catherine Walsh, Santiago Castro-Gómez, Carlos Walter Porto-Gonçalves, entre otros, a sus mejores 
representantes. En esa misma línea, se inscribe la propuesta teórica de Boaventura de Sousa Santos y su concepto de "ecología de saberes", un pensador del Norte global que, según Grosfoguel (2011, p. 97), se replantea sus sesgos eurocéntricos y se deja “contaminar” por las epistemologías del Sur. Dávalos nos apunta que “estas propuestas son críticas con el saber moderno y sus formas de reproducción institucional, en especial las universidades y los institutos de investigación", en las cuales se considera que "detrás de una episteme (verdad científica) existe siempre una estrategia de control y dominación”. En este sentido, la discusión epistemológica debe ir más allá de su "pertinencia científica y teórica y se convierta en un debate político", "la forma cómo se enseña, cómo se piensa y cómo se define lo Real, es decir lo existente en cuanto tal, rebasa los límites epistemológicos y metodológicos del conocimiento y se convierte en un asunto político que tiene ser debatido y comprendido desde la política porque implica al poder" (Dávalos, 2013, p. 2). En opinión de Dávalos,

El conocimiento moderno es a-moral. Es decir, sus coordenadas de pensamiento están por fuera de toda constricción ética. Desde las premisas del conocimiento moderno es imposible un conocimiento ético. La episteme moderna expulsa la ética de toda construcción teórica a nombre de la ciencia y su neutralidad valorativa. El conocimiento moderno es a-moral por definición y construcción. [...] Quien produce el conocimiento no es la sociedad, es el científico en un ambiente alienado de la sociedad, en la ocurrencia su laboratorio, su instituto de investigaciones, su gabinete de trabajo, su universidad o su empresa. El conocimiento que se produce es, por tanto, a-social. La sociedad no puede acceder a este conocimiento de forma libre, transparente y democrática. La sociedad tampoco consta como parte de ese proceso de creación intelectual. Es apenas un dato exógeno. Un instrumento o un medio. Un dato o un contexto. Nunca un sujeto activo. Los conflictos que desgarran a la sociedad nunca aparecen en la episteme dominante. [...] Por ello el saber se indexa. La construcción de un Index aleja de forma radical a la sociedad de la creación del conocimiento científico. Quien tiene acceso al Index no es la sociedad sino el científico que ha sido previamente reconocido y calificado como tal. Sin ese reconocimiento es imposible acceder al Index. Pero ese reconocimiento no es social ni democrático, sino interno a la estructura que asume el saber, en la ocurrencia, la universidad moderna (Dávalos, 2013, p. 3).

En el año 2000, los principales intelectuales poscoloniales de la "escuela" latinoamericana publicaron conjuntamente un libro titulado La colonialidad del saber: eurocentrismo y ciencias sociales, en el cual se intentaba dar respuesta a varias preguntas: ¿cuáles son las potencialidades que se están abriendo en el continente en el conocimiento, la política y en la cultura a partir del replanteo de estas cuestiones? ¿Cuál es la relación de estas perspectivas teóricas con el resurgir de las luchas de los pueblos históricamente excluidos como las poblaciones negras e indígenas en América Latina? ¿Cómo se plantean a 
partir de estos asuntos los (viejos) debates sobre la identidad, y en torno a la hibridez, la transculturación y a la especificidad de la experiencia histórico-cultural del continente? ¿Cuáles son hoy las posibilidades (y realidad) de un diálogo desde las regiones excluidas subordinadas por unos saberes coloniales y eurocéntricos (Asia, Africa, América Latina)? (Lander, 2000, p. 10). Entre los autores, se encuentran autores consagrados como Santiago Castro-Gómez, Fernando Coronil, Enrique Dussel, Arturo Escobar, Edgardo Lander, Francisco López Segrera, Walter D. Mignolo, Alejandro Moreno y Aníbal Quijano. Algunos de ellos son profesores en algunas prestigiosas universidades occidentales, especialmente en Estados Unidos.

Según Castro-Gómez, las teorías poscoloniales son "un ejemplo de la nueva conciencia de la inteligentsia respecto a sus propios límites”. Los intelectuales poscoloniales, como "sujetos transmigrantes", actúan de "agentes globales sin pertenencias fijas", sin representar directamente a los subalternos, y sin tener una identidad homogénea. Su intención es "crear espacios de resistencia frente a la colonización mundovital en sus propias localidades". Su crítica al colonialismo adquiere "un carácter teórico-práctico, en la medida en que participan activamente en la lucha por el control de los significados al interior de la teaching machine". Al igual que las narrativas anticolonialistas, identifican "la vinculación local, europea, de los discursos modernos sobre el «otro», como medio para desvirtuar sus pretensiones de universalidad", sabiendo que "su propia localización es un impedimento para acceder a la «totalidad»" (Castro-Gómez, 1998, p. 182).

Aníbal Quijano (2000) expone que la expansión del colonialismo europeo sobre el resto del mundo llevó a "la elaboración de la perspectiva eurocéntrica de conocimiento y con ella a la elaboración teórica de la idea de raza como naturalización de esas relaciones coloniales de dominación entre europeos y no-europeos", como una categoría mental de la modernidad (Quijano, 2000, p. 247). Según Quijano, la clasificación a una raza significó una nueva forma de "legitimar las ya antiguas ideas y prácticas de relaciones de superioridad/inferioridad entre dominados y dominantes", siendo "el más eficaz y perdurable instrumento de dominación social universal", según la cual, "los pueblos conquistados y dominados fueron situados en una posición natural de inferioridad y, en consecuencia, también sus rasgos fenotípicos, así como sus descubrimientos mentales y culturales" (Quijano, 2000, p. 247). 
La clasificación racial de la población y la temprana asociación de las nuevas identidades raciales de los colonizados con las formas de control no pagado, no asalariado, del trabajo, desarrolló entre los europeos o blancos la específica percepción de que el trabajo pagado era privilegio de los blancos. La inferioridad racial de los colonizados implicaba que no eran dignos del pago de salario. Estaban naturalmente obligados a trabajar en beneficio de sus amos. No es muy difícil encontrar, hoy mismo, esa actitud extendida entre los terratenientes blancos de cualquier lugar del mundo. Y el menor salario de las razas inferiores por igual trabajo que el de los blancos, en los actuales centros capitalistas, no podría ser, tampoco, explicado al margen de la clasificación social racista de la población del mundo. En otros términos, por separado de la colonialidad del poder capitalista mundial (Quijano, 2000, p. 249).

En aquella nueva situación de configuración cultural e intelectual, con una “incorporación de tan diversas y heterogéneas historias culturales a un único mundo dominado por Europa", se concentraron todas "las experiencias, historias, recursos y productos culturales" en poder de la hegemonía europea, la cual articuló todas estas nuevas incorporaciones en un solo "orden cultural global”. Europa controló "todas las formas de control de la subjetividad, de la cultura, y en especial del conocimiento, de la producción del conocimiento" de las poblaciones colonizadas con suma violencia. Estas poblaciones se vieron abocadas a convertirse en unas subculturas campesinas, iletradas, "despojándoles de su herencia intelectual objetivada". Así mismo, forzaron "a los colonizados a aprender parcialmente la cultura de los dominadores en todo lo que fuera útil para la reproducción de la dominación, sea en el campo de la actividad material, tecnológica, como de la subjetiva, especialmente religiosa". Un proceso que produjo a largo plazo "una colonización de las perspectivas cognitivas, de los modos de producir u otorgar sentido a los resultados de la experiencia material o intersubjetiva, del imaginario, del universo de relaciones intersubjetivas del mundo, de la cultura en suma" (Quijano, 2000, p. 251).

Quijano afirma, basándose en Wallerstein, que el éxito de Europa Occidental fue "convertirse en el centro del moderno sistema-mundo", lo cual desarrolló en los europeos y europeas "un rasgo común a todos los dominadores coloniales e imperiales de la historia", es decir, el etnocentrismo. Cuyo rasgo fundamental es la asociación entre ambos fenómenos, "el etnocentrismo colonial y la clasificación racial universal", lo que ayuda a explicar "por qué los europeos fueron llevados a sentirse no sólo superiores a todos los demás pueblos del mundo, sino, en particular, naturalmente superiores" (Quijano, 2000, p. 251), ya que los pueblos colonizados eran anteriores a los europeos, eran inferiores. Según Quijano, el eurocentrismo se elaboró como una perspectiva hegemónica de conocimiento basada en la 
trayectoria de la historia que "parte de un estado de naturaleza y culmina en Europa" (Quijano, 2000, p. 253).

La confrontación entre la experiencia histórica y la perspectiva eurocéntrica de conocimiento permite señalar algunos de los elementos más importantes del eurocentrismo: a) una articulación peculiar entre un dualismo (precapitalcapital, no europeo-europeo, primitivo-civilizado, tradicional-moderno, etc.) y un evolucionismo lineal, unidireccional, desde algún estado de naturaleza a la sociedad moderna europea; b) la naturalización de las diferencias culturales entre grupos humanos por medio de su codificación con la idea de raza; y c) la distorsionada reubicación temporal de todas esas diferencias, de modo que todo lo no-europeo es percibido como pasado. Todas estas operaciones intelectuales son claramente interdependientes. Y no habrían podido ser cultivadas y desarrolladas sin la colonialidad del poder (Quijano, 2000, p. 258).

Según Castro-Gómez, el mayor desafío radica en una "descolonización" de las ciencias sociales y la filosofía, para desmarcarse de ese dualismo que presenta Quijano, esas "categorías binarias con las que trabajaron en el pasado las teorías de la dependencia y las filosofías de la liberación (colonizador versus colonizado, centro versus periferia, Europa versus América Latina, desarrollo versus subdesarrollo, opresor versus oprimido, etc.)", ya que entiende que "no es posible conceptualizar las nuevas configuraciones del poder con ayuda de ese instrumental teórico" (Castro-Gómez, 2000, p. 159).

En opinión de Lander, con el inicio del colonialismo en América comienza "no sólo la organización colonial del mundo sino -simultáneamente- la constitución colonial de los saberes, de los lenguajes, de la memoria y del imaginario". En el siglo XIX, por primera vez, se organiza "la totalidad del espacio y del tiempo -todas las culturas, pueblos y territorios del planeta, presentes y pasados- en una gran narrativa universal" (Lander, 2000, p. 16).

Es éste el contexto histórico-cultural del imaginario que impregna el ambiente intelectual en el cual se da la constitución de las disciplinas de las ciencias sociales. Esta es la cosmovisión que aporta los presupuestos fundantes a todo el edificio de los saberes sociales modernos. Esta cosmovisión tiene como eje articulador central la idea de modernidad, noción que captura complejamente cuatro dimensiones básicas: 1) la visión universal de la historia asociada a la idea del progreso (a partir de la cual se construye la clasificación y jerarquización de todos los pueblos y continentes, y experiencias históricas); 2) la "naturalización" tanto de las relaciones sociales como de la "naturaleza humana" de la sociedad liberalcapitalista; 3) la naturalización u ontologización de las múltiples separaciones propias de esa sociedad; y 4) la necesaria superioridad de los saberes que produce esa sociedad ('ciencia') sobre todo otro saber (Lander, 2000, p. 22).

En cuanto al carácter universal del desarrollo histórico europeo, Lander afirma que 
las formas del conocimiento desarrolladas para la comprensión de esa sociedad se convierten en las únicas formas válidas, objetivas, universales del conocimiento. Las categorías, conceptos y perspectivas (economía, Estado, sociedad civil, mercado, clases, etc.) se convierten así no sólo en categorías universales para el análisis de cualquier realidad, sino igualmente en proposiciones normativas que definen el deber ser para todos los pueblos del planeta. Estos saberes se convierten así en los patrones a partir de los cuales se pueden analizar y detectar las carencias, los atrasos, los frenos e impactos perversos que se dan como producto de lo primitivo o lo tradicional en todas las otras sociedades (Lander, 2000, p. 23).

Lander añade que ésta es "una construcción eurocéntrica, que piensa y organiza a la totalidad del tiempo y del espacio, a toda la humanidad, a partir de su propia experiencia, colocando su especificidad histórico-cultural como patrón de referencia superior y universal”, pero también es un "dispositivo de conocimiento colonial e imperial" que articula "esa totalidad de pueblos, tiempo y espacio como parte de la organización colonial/imperial del mundo" que "normaliza " al ser humano y a la sociedad. En cambio, las "otras formas", es decir, del ser, de lo social y del saber son "trasformadas no sólo en diferentes, sino en carentes, en arcaicas, primitivas, tradicionales, premodernas", así son situadas en un momento anterior a la historia de la humanidad enfatizando su "inferioridad" (Lander, 2000, p. 24).

En este sentido, la Modernidad se presenta como un proceso cuya lectura, según Enrique Dussel, tiene dos sentidos. El primero es "eurocéntrico, provinciano, regional”, entendido como una "emancipación, una salida de la inmadurez por un esfuerzo de la razón como proceso crítico, que abre a la humanidad a un nuevo desarrollo del ser humano". Este proceso se efectuaría en Europa, esencialmente en el siglo XVIII (Dussel, 2000, p. 45). Esta visión eurocéntrica indica como "punto de partida de la Modernidad fenómenos intraeuropeos, y el desarrollo posterior no necesita más que Europa para explicar el proceso". Dussel propone una segunda visión de la "Modernidad", en un sentido mundial, la cual consiste en definir como "determinación fundamental del mundo moderno el hecho de ser (sus Estados, ejércitos, economía, filosofía, etc.) centro de la Historia Mundial" a partir de 1492, fecha en la que comenzó empíricamente la Historia Mundial y la iniciación del despliegue del "Sistema-mundo" de Wallerstein (1979). Dussel expone que "sólo con la expansión portuguesa desde el siglo XV, que llega al Extremo Oriente en el siglo XVI, y con el descubrimiento de América hispánica, todo el planeta se torna el lugar de una sola Historia Mundial" y Europa constituye, "por primera vez en la historia, a todas las otras culturas como su periferia" (Dussel, 2000, pp. 46-47). Dussel expone así el proceso de “periferización” en el mundo: 
Figura 1. Proceso de "periferización” en el mundo y significado, según Dussel.

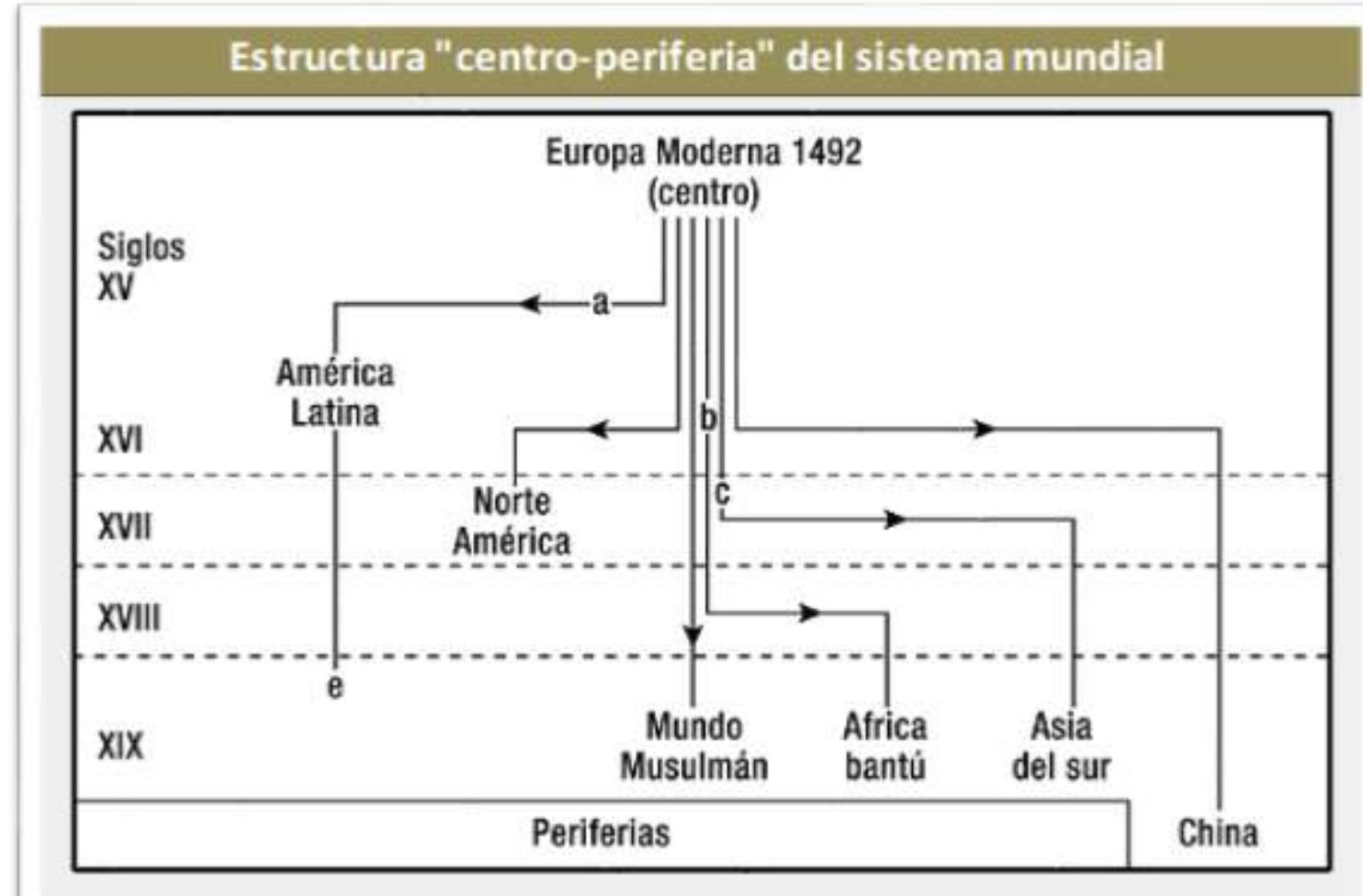

\begin{tabular}{|c|l|}
\hline Flecha & \multicolumn{1}{|c|}{ Significado } \\
\hline a & la primera periferia \\
\hline b & el esclavismo en sus costas occidentales \\
\hline c & $\begin{array}{l}\text { algunas colonias (como Goa, etc.), pero } \\
\text { sin ocupación continental }\end{array}$ \\
\hline d & emancipación de Estados Unidos \\
\hline e & emancipación hispanoamericana \\
\hline
\end{tabular}

Fuente: Dussel, 2000, p. 47.

Comienza, así, el mito de la Modernidad basado en el etnocentrismo europeo moderno, el cual Dussel lo describe como una autocomprensión superior, "lo que significará sostener sin conciencia una posición ideológicamente eurocéntrica" y con una "exigencia moral" de desarrollar a los pueblos primitivos siguiendo el proceso educativo europeo de desarrollo unilineal. Este proceso de modernización debe hacerse aunque sea necesaria la ayuda de la fuerza bélica y la dominación de estos pueblos colonizados (Dussel, 2000, p. 49).

Para la superación de la "Modernidad", si es que se pretende, Dussel afirma que "será necesario negar la negación del mito de la Modernidad", y para ello, la "otra-cara negada y victimada de la Modernidad debe primeramente descubrirse como inocente: es la víctima 
inocente del sacrificio ritual, que al descubrirse como inocente juzga a la Modernidad como culpable de la violencia sacrificadora, conquistadora originaria, constitutiva, esencial".

Sólo cuando se niega el mito civilizatorio y de la inocencia de la violencia moderna, se reconoce la injusticia de la praxis sacrificial fuera de Europa (y aún en Europa misma), y entonces se puede igualmente superar la limitación esencial de la "razón emancipadora". Se supera la razón emancipadora como "razón liberadora" cuando se descubre el "eurocentrismo" de la razón ilustrada, cuando se define la "falacia desarrollista" del proceso de modernización hegemónico. Esto es posible, aún para la razón de la Ilustración, cuando éticamente se descubre la dignidad del Otro (de la otra cultura, del otro sexo y género, etcétera); cuando se declara inocente a las víctimas desde la afirmación de su Alteridad como Identidad en la Exterioridad como personas que han sido negadas por la Modernidad (Dussel, 2000, p. 50).

Dussel propone dos paradigmas "contradictorios": el de la "Modernidad eurocéntrica", y el de la "Modernidad subsumida desde un horizonte mundial", la cual efectuó una función "ambigua ", por un lado, “como emancipación” y, por otro, "como mítica cultura de la violencia". Para Dussel, la Modernidad se definió "como emancipación con respecto al nosotros, pero no advirtió su carácter mítico-sacrificial con respeto a los otros" (Dussel, 2000, p. 51). Dussel explica con el siguiente esquema el proceso de los dos paradigmas de la Modernidad: 
Figura 2. Procesos históricos de los dos paradigmas de la Modernidad y su comprensión.

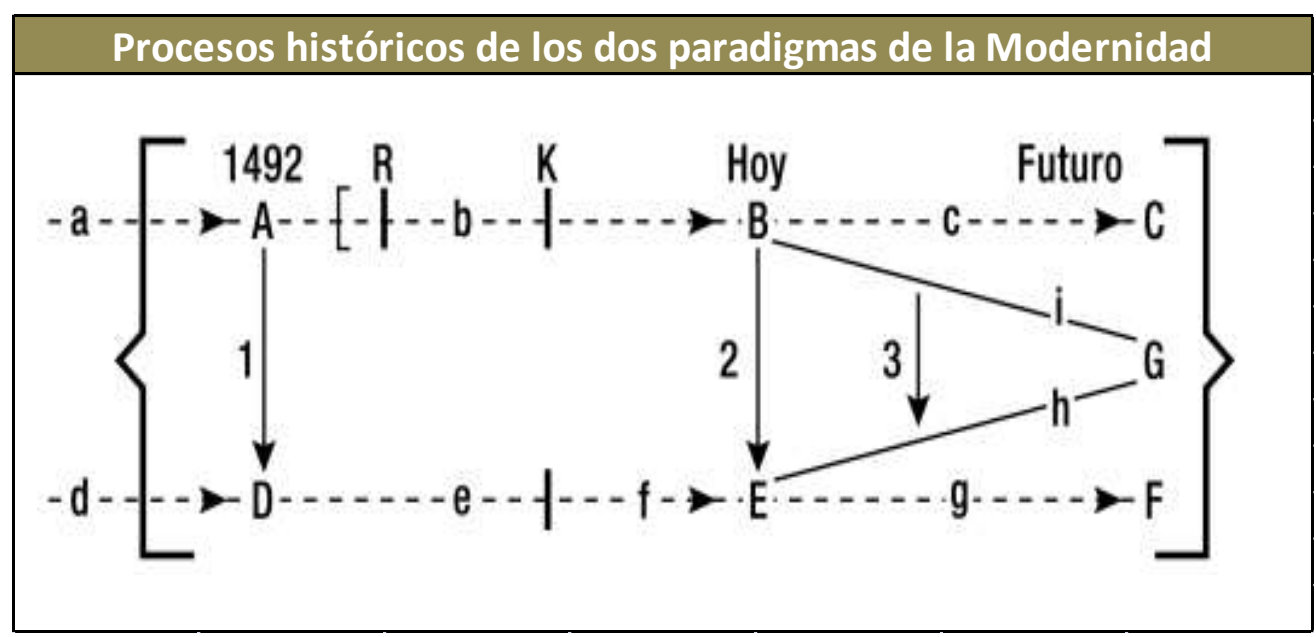

\begin{tabular}{|c|c|c|}
\hline \multicolumn{3}{|c|}{ Comprensión de los dos paradigmas de la modernidad de Dussel } \\
\hline \multicolumn{2}{|r|}{ I) Determinaciones más relevantes: } & II) Relaciones con una cierta dirección o flechas: \\
\hline A & Europa en el momento del "descubrimiento" (1492) & a Historia europea medieval (lo pre-moderno europeo) \\
\hline B & El presente europeo moderno & \begin{tabular}{l|l} 
b & Historia "moderno"-europea \\
\end{tabular} \\
\hline C & Proyecto de "realización" (habermasiana) de la "Modernida & c Praxis de realización de $C$ \\
\hline D & $\begin{array}{l}\text { La "invasión" del continente (de Africa y Asia } \\
\text { posteriormente) }\end{array}$ & d $\begin{array}{l}\text { Historias anteriores a la conquista europea (América } \\
\text { Latina, Africa y Asia) }\end{array}$ \\
\hline $\mathbf{E}$ & El presente "periférico" & e Historia colonial y dependiente mercantilista \\
\hline $\mathbf{F}$ & Proyecto dentro del "Nuevo Orden Mundial" dependiente & f Historia del mundo periférico al capitalismo industrial \\
\hline G & Proyecto mundial de liberación ("Trans-modernidad") & g Praxis de realización de $F$ (desarrollismo) \\
\hline $\mathbf{R}$ & Mercantilismo hispánico (Renacimiento y Reforma) & h Praxis de liberación o de realización de $G$ \\
\hline $\mathrm{K}$ & Capitalismo industrial (La "Aufklärung") & \begin{tabular}{l|l} 
i & Praxis de solidaridad del Centro con la Periferia \\
\end{tabular} \\
\hline \multicolumn{3}{|c|}{$1,2,3, n$ : Tipos históricos de dominación (de $A \rightarrow D$, etc.) } \\
\hline \multicolumn{3}{|c|}{ III) Los dos paradigmas de la Modernidad } \\
\hline & Paradigma eurocéntrico de "Modernidad": [R->K->B->C] & \{\} $\begin{array}{l}\text { Paradigma mundial de "Modernidad/Alteridad" (hacia } \\
\text { una "Trans-modernidad"): }\{A / D->B / E->G\}\end{array}$ \\
\hline
\end{tabular}

Fuente: elaboración propia en base a Dussel, 2000, p. 52.

En la práctica de la descolonialización, Walsh asume la propuesta de Amawtay Wasi, en el cual se encuentra el potencial y la posibilidad para construir un camino hacia la descolonización del saber, basado en tres puntos clave:

1. considerar que el conocimiento tiene "valor, color, género y lugar de origen y, por eso, el lugar desde donde uno piensa sí importa”.

2. recuperar, revalorizar y aplicar los saberes ancestrales. 
3. No se trata simplemente de relacionar conocimientos (ancestrales, occidentales, orientales) como si fueran bloques herméticos, sino de considerarlo como "procesos de intervención intelectual, en la creación de conocimientos y de modos de pensar que cruzan fronteras" (Walsh, 2004, p. 4).

De esta manera, la colonialidad del poder va pasando al campo de saber, descartando la noción del indígena como intelectual, como alguien que puede intervenir directamente en la producción de conocimiento. Y como parte esencial de esta colonialidad del saber, se mantiene la hegemonía del eurocentrismo como única perspectiva de conocimiento (Walsh, 2004, p. 2).

\section{Conclusiones.}

El estudio ha comparado e interconectado los aportes teóricos de algunos de los autores y autoras más relevantes en América Latina que han contribuido al debate poscolonial en los comienzos del siglo XXI. En esta reunión de intelectuales, se expresa la necesidad de encontrar un corpus teórico sobre la poscolonialidad que sea aplicable al proceso de descolonización de las mentes latinoamericanas. La revalorización de las epistemologías del sur constituye un factor importante con el fin de alcanzar unas identidades emancipadas y no coloniales dentro de la hibridez cultural en la posmodernidad.

La superación de la mentalidad eurocéntrica es uno de los caminos que se han de seguir para encontrar una práctica poscolonizadora. Se trata de construir una praxis que revalorice los conocimientos y saberes de las culturas tradicionales en diálogo con el saber hegemónico occidental. Estos autores citados en el texto contribuyen a promocionar los saberes del Sur global, subalternos e indígenas, para superar las relaciones de dependencia cultural y política.

En este sentido, aparecen nuevos espacios y contextos donde poder analizar e investigar estos procesos poscoloniales en posteriores investigaciones, como son: el aporte epistemológico que se desarrolla desde las Universidades indígenas, el fomento de talleres de ciencia que propicie una ecología de saberes (Santos), el estudio de las dinámicas en la movilidad internacional de estudiantes y profesorado o la cooperación Sur-Sur en el ámbito educativo. 


\section{Bibliografía.}

BHABHA, H.K. (2002). El lugar de la cultura. Buenos Aires: Manantial.

CASTRO-GÓMEZ, S. (1998). Geografías poscoloniales y translocalizaciones narrativas de lo latinoamericano. In Follari, R. y Lanz, R. (Comps.). Enfoque sobre posmodernidad en América Latina. Caracas: Sentido. Pp. 155-182.

CASTRO-GÓMEZ, S. (2005). La postcolonialidad explicada a los niños. Popayán: Universidad del Cauca.

CHAMBERS, I (2006). La cultura después del humanismo: historia, cultura, subjetividad. Madrid: Cátedra.

DÁVALOS, P. (2013). Apuntes sobre la colonialidad y decolonialidad del saber: A propósito de las reformas universitarias en el Ecuador. Rebelión, www.rebelion.org/noticia.php?id=167244.

DUSSEL, E. (2000). Europa, modernidad y eurocentrismo. In Lander, E. (comp.) La colonialidad del saber: eurocentrismo y ciencias sociales. Perspectivas Latinoamericanas. Buenos Aires: CLACSO, Consejo Latinoamericano de Ciencias Sociales.

FANON, F. (1999). Los condenados de la tierra. Tafalla: Txalaparta.

GROSFOGUEL, R. (2011). La descolonización del conocimiento: diálogo crítico entre la visión decolonial de Frantz Fanon y la sociología descolonial de Boaventura de Sousa Santos. In VV.AA., Formas-Otras: Saber, nombrar, narrar, hacer. Barcelona: CIDOB, pp. $97-108$.

HALL, S. (1996). New Ethnicities. In Morley, D. et al. (eds.), Stuart Hall: Critical Dialogues in Cultural Studies. London/New York: Routledge.

HAWLEY, J.C. (2001). Encyclopedia of Postcolonial Studies. USA: Greenwood.

LANDER, E. (2000). Ciencias sociales: saberes coloniales y eurocéntricos. In Lander, E. (comp.) La colonialidad del saber: eurocentrismo y ciencias sociales. Perspectivas Latinoamericanas. Buenos Aires: CLACSO, Consejo Latinoamericano de Ciencias Sociales.

MELLINO, M. (2008). La crítica poscolonial: descolonización, capitalismo y cosmopolitismo en los estudios coloniales. Buenos Aires: Paidós.

MEMMI, A. (1974). Retrato del colonizado precedido por Retrato del colonizador. Madrid: EDICUSA.

MESSEGUER, P. (2006). Traducción y literatura poscolonial africana: los Realia. http://www.translationactivism.com/articles/Puri_Messeguer.

MIGNOLO, W. (1995). La razón postcolonial: herencias coloniales y teorías postcoloniales. Revista chilena de literatura, $\mathrm{n}^{\circ}$ 47, pp. 91-114.

QUIJANO, A. (2000). Colonialidad del poder, eurocentrismo y América Latina. In Lander, E. (comp.) La colonialidad del saber: eurocentrismo y ciencias sociales. Perspectivas Latinoamericanas. Buenos Aires: CLACSO, Consejo Latinoamericano de Ciencias Sociales. 
ROBOTHAM, D. (1997). El poscolonialismo: el desafío de las nuevas modernidades.

Ponencia de Honor, American Ethnological Society.

SAID, E. (1990). Orientalismo. Barcelona: Libertarias.

SAID, E. (1996). Cultura e imperialismo. Barcelona: Anagrama.

SAID, E. (2009). Sobre la Universidad. CyE. Año I, n 2 Primer Semestre.

SANTOS, B.S. (2002). Between Prospero and Caliban: Colonialism, Postcolonialism and Inter-identity. Luso-Brazilian Review, 39/2, pp. 9-43.

SHARP, J.P. (2009). Geographies of Postcolonialism. London: SAGE

SOJA, E.W. (2008). Postmetrópolis. Estudios críticos sobre las ciudades y las regiones. Madrid: Traficantes de sueños.

SPIVAK, G.Ch. (1990). The post-colonial critic: interviews, strategies and dialogues. New York: Routledge.

VEGA, M. J. (2003). Imperios de papel. Introducción a la crítica postcolonial. Barcelona: Crítica.

WALSH, C. (2004). Geopolíticas del conocimiento, interculturalidad y descolonialización. Boletín ICCI-ARY Rimay, Año 6, No. 60.

\section{Recebido em: 04/04/2017. Aceito em: 23/08/2017.}

